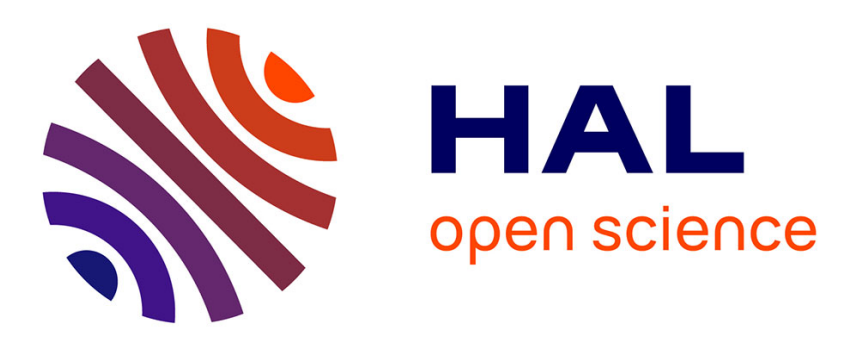

\title{
The metrology and applications of PSD (position sensitive detector) sensors for microrobotics.
}

Ioan Alexandru Ivan, Mihai Ardeleanu, Guillaume J. Laurent, Ning Tan, Cédric Clévy

\section{- To cite this version:}

Ioan Alexandru Ivan, Mihai Ardeleanu, Guillaume J. Laurent, Ning Tan, Cédric Clévy. The metrology and applications of PSD (position sensitive detector) sensors for microrobotics.. International Symposium on OptoMechatronic Technologies., Oct 2012, Paris, France. pp.1-2. hal-00797889

\section{HAL Id: hal-00797889 \\ https://hal.science/hal-00797889}

Submitted on 7 Mar 2013

HAL is a multi-disciplinary open access archive for the deposit and dissemination of scientific research documents, whether they are published or not. The documents may come from teaching and research institutions in France or abroad, or from public or private research centers.
L'archive ouverte pluridisciplinaire HAL, est destinée au dépôt et à la diffusion de documents scientifiques de niveau recherche, publiés ou non, émanant des établissements d'enseignement et de recherche français ou étrangers, des laboratoires publics ou privés. 


\title{
The metrology and applications of PSD (position sensitive detector) sensors for microrobotics
}

\author{
Ioan Alexandru IVAN, Mihai ARDELEANU* \\ University Valahia of Targoviste, FIE\&FIMMR \\ Targoviste, Romania \\ ivan@valahia.ro , mihai.ardeleanu@ valahia.ro
}

\author{
Guillaume J. LAURENT, Ning TAN, Cédric CLEVY \\ FEMTO-ST Institute, UMR CNRS-6174 / UFC / ENSMM \\ / UTBM, Dpt. AS2M, Besancon, France \\ guillaume.laurent@femto-st.fr, ning.tan@femto-st.fr , \\ cedric.clevy@femto-st.fr
}

\begin{abstract}
PSD) are special special monolithic PIN photodiodes featuring a series of lateral electrodes in order to achieve a 1D or 2D displacement measurement of an optical spot. Compared to the discrete array sensors, the PSD have many advantages including high positioning resolution, fast response time and very simple analogue signal conditioning circuits. This paper investigates the metrology of a two-dimensional PSD working alternately in direct or indirect (reflective) mode. The possible applications consist in precise assembly of optical MEMS micromirrors or fast tracking of an object over a pneumatic smart-surface. The first results showed a good linearity and a fast response time, which successfully enable such applications for PSD sensors.
\end{abstract}

Keywords: microrobotics, optics, optomechatronics, sensing, PSD position sensitive detector, smart-surface, MOEMS.

\section{INTRODUCTION}

The micro-robotic applications often involve high dynamics control. Rapid sensors for micro-objects positioning are thus required, combining high accuracy and repeatability, some important features required to attain a precised loop controls. In the microrobotics area, the control usually relies on camerabased visual servoing (VS) techniques [1] or on external sensors such as interferometers or laser triangulators. In the first case, the VS-based applications may require extensive computing resources especially in the case of fast dynamics systems. This may be the case of a fast object manipulation (in under 0.1 seconds) over a pneumatically-actuated microconveyor called smart-surface [2]. On the second case, the bulky external sensors prevent multiple degrees-offreedom (DoF) evaluation in such confined spaces. This is the case for hybrid MOEMS assembly such as [3] where precise micromirror alignment in 3 separate DoFs (translation and tilt) is required. Therefore, for both simplicity and costeffectiveness reasons, we investigated the PSD sensors suitability in these two stated applications.

The potential of the PSDs are in many fields of activity, as some cost-effective sensors generating continuous and lag-free data easily embeddable into even low power microcontrollerbased PID controllers. Regarding the existing PSD applications, actually they are quite dispersed, for instance aeronautics, civil engineering [4], surgery [5] etc., all using

*Corresponding author: mihai.ardeleanu@ valahia.ro light sources (e.g. laser, led) projected by lens or mirrors over the $1 \mathrm{D}$ or $2 \mathrm{D}$ PSD surfaces.

To test the performance of this kind of sensor for the microrobotic applications [2][3], this short paper shows a comparative analysis between a commercially-available PSD[6], a closed-loop piezoelectric nano-translation cube and a precise (but slow) video camera, respectively.

\section{THE PSD IN DIRECT (LASER SPOT) MODE}

Figure 1 presents the tested Hamamatsu commercial PSD unit model no. S5990-01, featuring a two-dimensional squared $4 \times 4 \mathrm{~mm}^{2}$ sensing area. The output analogue signals are directly proportional to the distance between the corners and the light spot position The manufacturer formula for the $x-y$ coordinates of a laser or LED spot focused on the surface is:

$$
\begin{aligned}
& x=\frac{L}{2} \times \frac{\left(I_{2}+I_{3}\right)-\left(I_{1}+I_{4}\right)}{I_{1}+I_{2}+I_{3}+I_{4}} \\
& y=\frac{L}{2} \times \frac{\left(I_{2}+I_{4}\right)-\left(I_{1}+I_{3}\right)}{I_{1}+I_{2}+I_{3}+I_{4}}
\end{aligned}
$$

where $\mathrm{L}$ is the side of the square $(4 \mathrm{~mm})$ and $I_{1}$ to $I_{4}$ are the values of the four anode currents .

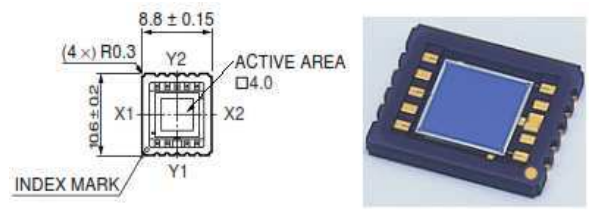

Figure 1. PSD unit, Hamamatsu S5990-01datasheet.

The custom-designed electronic circuit consisted of four transimpedance amplifiers to convert and amplify the $I_{1}$ to $I_{4}$ signals. It is based on a single-stage schematic featured with precision low noise and low bias currents op-amps (OPA111).

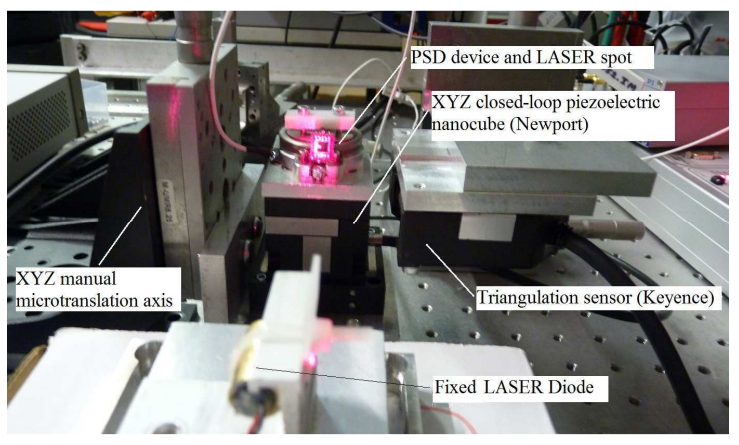

Figure 2. The experimental PSD setup in direct laser spot mode. 
The output signals for such typical circuits are:

$$
V_{\text {out } \_1 \ldots 4}=-R \cdot I_{1 \ldots 4}
$$

where $R$ is the feedback resistance (exact values $4.7 \mathrm{k} \Omega$ in direct mode and $2.2 \mathrm{M} \Omega$ in indirect mode).

Figure 2 shows the elements of the first experimental setup in direct mode. The red laser diode power was of $3 \mathrm{~mW}$, spot focused in $0.2 \mathrm{~mm}$ diameter. A closed-loop surface scan was performed in a squared shaped manner thanks to a strain gage piezoelectric nanocube.

Formulas (1-2) have been entered into a rapid control prototyping board. No further signal filtering or quadratic calibration has been performed to increase the accuracy. After a transient period, the strain gage and PSD signals successfully align (Fig. 3). The maximum error is of $\pm 3 \mu \mathrm{m}$ and $\pm 1 \mu \mathrm{m}$ in $x$ and $y$ directions, respectively. The PSD repeatability is under $1 \mu \mathrm{m}$. The RMS (root mean square) noise figure is of $0.25 \mu \mathrm{m}$ which shows excellent, sub-micrometer resolution. If such a PSD device would be positioned at a $3 \mathrm{~cm}$ distance from a MOEMS mirror [3] the achieved $\theta-\varphi$ tilt positioning accuracy would be in under $\pm 0.006^{\circ}$.
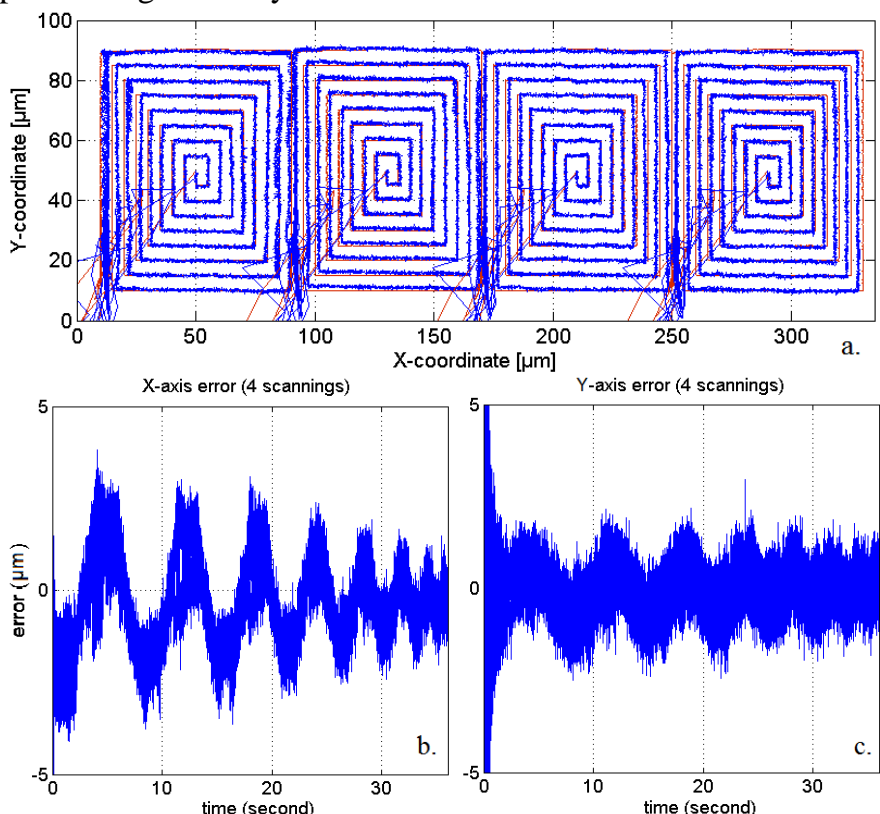

Figure 3. Experiments with direct laser spot. a) Scan of an XY surface, reference is in red, PSD signal is in blue. $\mathrm{b}, \mathrm{c}) \mathrm{X}$ and $\mathrm{Y}$ scan errors.

\section{THE PSD IN INDIRECT (DIFFUSE REFLECTIVITY) MODE}

Unlike the typical applications where a light spot is focused on the PSD surface, a second system was designed to work in the diffuse reflectivity mode under epi-illumination, where the diffuse object was projected over the PSD surface (Figure 4). Such application would apply to circular or squared objects. For metrology reasons, a regular camera has been connected to the same optical port by means of a beam splitter and synchronously triggered with the PSD acquisition.

As the PSD currents are under the $\mu \mathrm{A}$, the LED lighting stroboscopic was driven in a stroboscopic manner. The results depicted in Figure 5 show a very good correlation between the fast PSD acquisition (500 fps) and the slower CCD camera (33 fps).

The noise RMS value is of $5.8 \mu \mathrm{m}$ for a stroboscopic lighting fill factor $F F=1: 11$. The maximum error in this diffuse reflectivity mode is under $50 \mu \mathrm{m}$ with a simple four-point linear calibration. The maximum relative error being less than $1.5 \%$ over the entire measurement range.

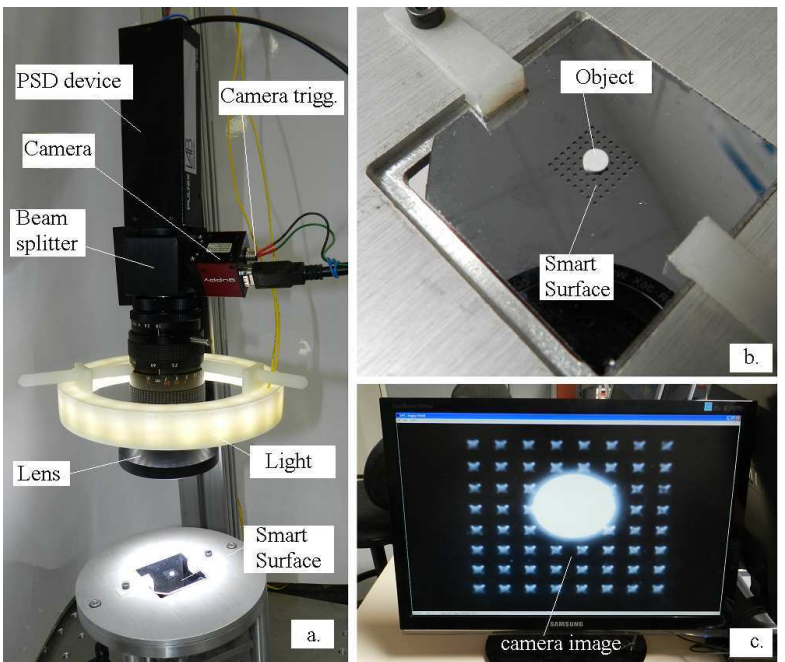

Figure 4. The experimental Smart-Surface and PSD sensory system.

a) General setup view. b) Zoom of the Smart-Surface. c) Camera capture.

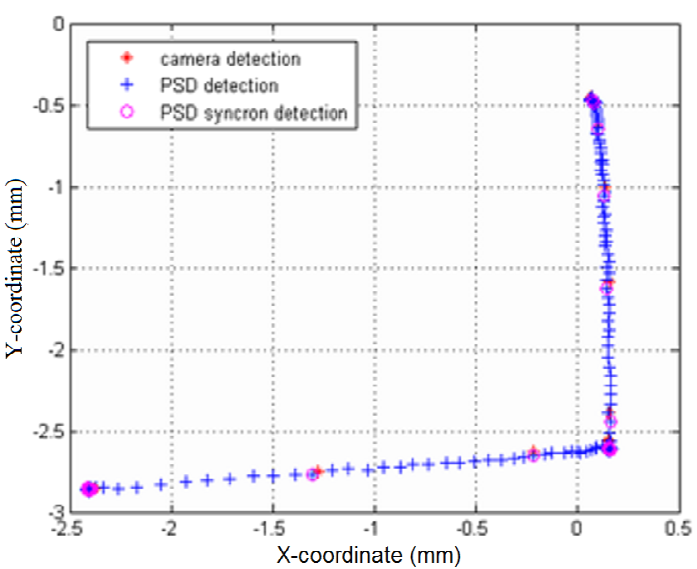

Figure 5. Open-loop object actuation by a smart-surface. The superposition of the indirect-mode PSD and of the camera trajectories shows a good correlation. Acquisition periods are $2 \mathrm{~ms}$ for PSD and $30 \mathrm{~ms}$ for camera.

\section{ACKNOWLEDGEMENTS}

These works were supported under the Romanian UEFISCDI Project "Advanced devices for micro and nanoscale manipulation and characterization - ADMAN" (PN-II-RU-TE-2011-3-0299). These works were also partially supported by the NRA (French National Research Agency) project "Smart Blocks" (ANR-2011-BS03-005).

\section{REFERENCES}

[1] Xinhan Huang, Xiangjin Zeng, Min Wang, "The uncalibrated microscope visual servoing for micromanipulation robotic system" Chapter III in "Visual Servoing" book, Edited by Rong-Fong Fung, 234 pages, Publisher: InTech, April, 2010

[2] Réda Yahiaoui, Rabah Zeggari, Julien Malapert, Jean-François Manceau, "A MEMS-based pneumatic micro-conveyor for planar micromanipulation", Mechatronics , vol. 22, issue 5, pp. 515-521, August 2012

[3] S. Bargiel, K. Rabenorosoa, C. Clévy, C. Gorecki and P. Lutz, "Towards Micro-Assembly of Hybrid MOEMS Components on Reconfigurable Silicon Free-Space Micro-Optical Bench", Journal of Micromechanics and Microengineering 20, 4 (2010), 20 pages.

[4] Iwao Matsuya, Ryuta Katamura, Maya Sato, Miroku Iba, Hideaki Kondo , Kiyoshi Kanekawa, Motoichi Takahashi, Tomohiko Hatada, Yoshihiro Nitta, Takashi Tanii, Shuichi Shoji, Akira Nishitani, "Measuring relative-story displacement and local inclination angle using multiple position-sensitive detectors", Sensors, vol. 10, pp. 9687-9697, 2010

[5] Rafael Mario Ortiz,Cameron Riviere, "Tracking rotation and translation of laser microsurgical instruments", Proceedings of the 25th Annual International Conference of the IEEE Engineering in Medicine and Biology Society, pp. 3411 - 3414, September, 2003

[6] jp.hamamatsu.com/en/product_info/index.html 